\title{
Prevention and management of delirium in critically ill adult patients in the intensive care unit: a review based on the 2018 PADIS guidelines
}

\author{
Seung Yong Park, Heung Bum Lee \\ Department of Internal Medicine, Research Center for Pulmonary Disorders, Chonbuk National University Medical School, Jeonju, Korea
}

Delirium is an acute, confusional state characterized by altered consciousness and a reduced ability to focus, sustain, or shift attention. It is associated with a number of complex underlying medical conditions and can be difficult to recognize. Many critically ill patients (e.g., up to $80 \%$ of patients in the intensive care unit [ICU]) experience delirium due to underlying medical or surgical health problems, recent surgical or other invasive procedures, medications, or various noxious stimuli (e.g., underlying psychological stressors, mechanical ventilation, noise, light, patient care interactions, and drug-induced sleep disruption or deprivation). Delirium is associated with a longer duration of mechanical ventilation and ICU admittance as well as an increased risk of death, disability, and long-term cognitive dysfunction. Therefore, the early recognition of delirium is important and ICU medical staff should devote careful attention to both watching for the occurrence of delirium and its prevention and management. This review presents a brief overview of delirium and an update of the literature with reference to the 2018 Society of Critical Care Medicine Clinical Practice Guidelines for the Prevention and Management of Pain, Agitation/Sedation, Delirium, Immobility, and Sleep Disruption in Adult Patients in the ICU.

Key Words: delirium; guidelines; intensive care units; prevention and control

\section{DEFINITION}

The American Psychiatric Association (in the Diagnostic and Statistical Manual of Mental Disorders, fifth edition) defines delirium based on the following five criteria: (1) disturbance in attention (i.e., a reduced ability to direct, focus, sustain, and shift attention) and awareness; (2) a disturbance that develops over a short period of time (usually hours to days), represents a change from baseline, and tends to fluctuate during the day; (3) an additional disturbance in cognition (e.g., memory deficit, disorientation, language, visuospatial ability, or perception); (4) a disturbance that is not better explained by another preexisting, evolving, or established neurocognitive disorder and which does not occur in the context of a severely reduced level of arousal, such as coma; and (5) when there is evidence from medical or familial history, physical examination, or laboratory tests that the disturbance is caused by a medical condition, substance intoxication or withdrawal, or medication side effect [1]. Symptoms are often accompanied by sleep disturbance, abnormal psychomotor activity, and emotional dis-

\section{Review Article}

Received: February 9, 2019

Accepted: February 16, 2019

Corresponding author

Heung Bum Lee

Department of Internal Medicine, Chonbuk National University Medical School, 20 Geonji-ro, Deokjin-gu, Jeonju 54907, Korea

Tel: $+82-63-250-1685$

Fax: +82-63-250-1633

E-mail: Ihbmd@jbnu.ac.kr

Copyright @ 2019 The Korean Society of Critical Care Medicine

This is an Open Access article distributed under the terms of Creative Attributions Non-Commercial License (http:// creativecommons.org/li-censes/by-nc/4.0/) which permits unrestricted noncommercial use, distribution, and reproduction in any medium, provided the original work is properly cited. 
turbance.

Delirium is further differentiated according to the level of alertness; the motoric subtypes consist of the hyperactive, hypoactive, and mixed subtypes [2]. Patients with hyperactive delirium are aggressive, agitated, hallucinative, deluded, and exhibit increased psychomotor activity. In comparison, patients with hypoactive delirium have reduced alertness, lethargy, decreased responsiveness, and slowed motor skills. Patients with mixed subtypes of delirium fluctuate between hyperactive and hypoactive delirium. In the intensive care unit (ICU) setting, the prevalence values for the different subtypes of delirium are $1.6 \%$ for the hyperactive subtype, $43.5 \%$ for the hypoactive subtype, and $54.1 \%$ for the mixed subtype [2-4]. However, hypoactive delirium can easily be missed; more than $76 \%$ of total cases of hypoactive delirium are overlooked in the absence of a routine delirium screening. Study results indicate that the prognosis of delirium varies by subtype [5-7].

\section{CLINICAL SIGNIFICANCE OF ICU DELIRIUM}

ICU delirium is a predictor of increased mortality, prolonged hospital stay and mechanical ventilation, and greater costs as well as increased risks of reintubation and of transferring the affected patient to a long-term health care facility [8-11]. Delirium has an adverse impact on the post-discharge life of patients. Patients who had prolonged delirium showed poorer global cognition after discharge and greater risks of dementia and long-term cognitive impairment regardless of the severity and duration of their delirium [12-14].

\section{RISK FACTORS}

The causes of delirium are multifactorial. Risk factors can be separated into predisposing factors and precipitating factors

Table 1. Risk factors for delirium [15]

\begin{tabular}{|c|c|c|}
\hline Host factor & Acute illness & $\begin{array}{l}\text { latrogenic and } \\
\text { environmental factor }\end{array}$ \\
\hline $\begin{array}{l}\text { Age } 65 \text { years or older } \\
\text { Male sex } \\
\text { Alcoholism } \\
\text { Apolipoprotein E4 } \\
\text { polymorphism } \\
\text { Dementia } \\
\text { History of delirium } \\
\text { Depression } \\
\text { Hypertension } \\
\text { Smoking } \\
\text { Vision or hearing } \\
\text { impairment }\end{array}$ & $\begin{array}{l}\text { Acidosis } \\
\text { Anemia } \\
\text { Fever } \\
\text { Infection } \\
\text { Sepsis } \\
\text { Metabolic disturbances } \\
\text { (e.g., sodium, calci- } \\
\text { um, blood urea nitro- } \\
\text { gen, bilirubin) } \\
\text { Respiratory distress }\end{array}$ & $\begin{array}{l}\text { Immobilization } \\
\text { Medication (e.g., opi- } \\
\text { oids, benzodiaze- } \\
\text { pines) } \\
\text { Anticholinergic drug } \\
\text { Sleep disturbance }\end{array}$ \\
\hline
\end{tabular}

\section{KEY MESSAGES}

- Delirium is common in critically ill adults. Minimizing sedation is important for the prevention of delirium.

- Use of benzodiazepines should be avoided in the intensive care unit, except for the treatment of specific conditions.

- Dexmedetomidine administration can be considered for delirium in mechanically ventilated adults where agitation precludes weaning/extubation.

(Table 1) [15]. Age is one of the most important risk factors associated with delirium in the ICU $[16,17]$. Other major host factors include previous dementia, hypertension, chronic illness, poor nutrition, substance withdrawal, tobacco use, and depression. Iatrogenic and other potentially modifiable factors include hypoxia, metabolic and electrolyte imbalances, infection, dehydration, hyperthermia, sepsis, psychoactive medications, a preceding period of sedation, coma, mechanical ventilation, and sleep deprivation [18-22]. Environmental variables that increase the risk of developing delirium in the ICU include isolation, absence of visits, absence of visible daylight, transfer from another ward, immobility, and the use of physical restraints [23,24]. Among the medications used for sedation during ICU care, benzodiazepines have been identified as an independent risk factor for the development of delirium $[17,24,25]$. However, evidence of an association between the use of opioid medications and the development of delirium remains inconsistent [9].

Postoperative delirium is a well-researched topic. Perioperative risk factors for delirium include intraoperative blood loss, transfusion, low hematocrit, pain, preoperative atrial fibrillation, and a longer surgery time [26-30]. Delirium is associated with high perioperative plasma cortisol levels in patients undergoing coronary artery bypass graft surgery and systemic corticosteroid treatment in patients with acute lung injury [31, 32]. Among medications used in the ICU, antihistamines and furosemide can cause delirium as a consequence of their central anticholinergic effects [8].

\section{PATHOGENESIS}

The biological basis of delirium and confusion remains poorly understood, in part because it is difficult to evaluate severely ill patients using conventional electrophysiologic tests, brain imaging, and neurotransmitter assays. Furthermore, proposed animal models of delirium are not well-developed or validat- 
ed at this time. Despite these limitations, some important results about the pathophysiology of delirium have been reported to date.

First, imbalances or derangements of multiple neurotransmitter systems have been implicated in the pathophysiology of delirium. Cerebrospinal fluid studies of patients with delirium reveal alterations in neuropeptides [33]. Acetylcholine is one of the major neurotransmitters involved in ascending reticular activating system function and plays a key role in the pathogenesis of delirium [34]. A reduction in cholinergic function leads to increased levels of glutamate, dopamine, and norepinephrine in the brain. Decreased serotonin and gamma-aminobutyric acid levels also possibly contribute to the pathogenesis of delirium [35,36]. Anticholinergic drugs cause delirium when given to healthy volunteers and are even more likely to lead to acute confusion in the elderly [37]. With respect to hyper- or hypoactive delirium, dopamine excesses may contribute to hyperactive delirium, which has been linked with simultaneous acetylcholine decreases. Thus, acetylcholine and dopamine may be inversely related in delirium pathogenesis; pharmacological and neuroanatomical evidence also support this model [38]. Separately, norepinephrine plays an important role in modulating attention, anxiety, and mood; like dopamine, excess noradrenergic activity has been associated with hyperactive delirium [39].

Inflammatory mediators (e.g., cytokines, chemokines) are readily expressed during critical illness, trauma, and sepsis and following surgical intervention. Sepsis, severe sepsis, and septic shock are characterized by significantly elevated C-reactive protein, S-100 $\beta$ protein, and cortisol levels in patients with delirium versus without $[40,41]$. Proinflammatory cytokines (e.g., tumor necrosis factor- $\alpha$, interleukin-1 family cytokines) and chemokines are associated with endothelial damage in the central nervous system, thrombin formation, and microvascular dysfunction; importantly, these events can result in delirium. A study of ICU patients found that higher levels of procalcitonin at the time of ICU admission are associated with prolonged durations of brain dysfunction. Trends in higher levels of C-reactive protein also suggest a possible association with delirium [42]. However, it is difficult to exclude the confounding effects of underlying illness or dementia.

\section{RECOGNITION AND DIAGNOSIS OF DELIRIUM}

Delirium is common in critically ill adults $[3,4]$. However, the use of ICU delirium screening tools appears to be uncommon. For example, only $53 \%$ of ICU nurses perform delirium assess- ments [43]. Early recognition of delirium is important, if only to avoid prolonging its duration due to exacerbation by iatrogenic factors. Clinicians must employ tools that allow for a timely, accurate assessment of patients in various settings to be completed. Recognition is more difficult in the ICU setting because a patient may have a purposefully altered sensorium secondary to the sedation administered for procedures, pain control, or mechanical ventilation. Therefore, the assessment of a patient for delirium in the ICU is a two-step process because the clinician must first determine the current level of sedation before the actual assessment can be performed. Scales that can be used to assess sedation include the Ramsay Sedation Scale [44], the Riker Sedation-Agitation Scale [45], and the Richmond Agitation-Sedation Scale (RASS) [46,47].

It is appropriate for the clinician to check for the presence of delirium after the level of sedation has been determined and the patient is deemed responsive to a verbal stimulus. Multiple instruments have been validated for use in non-ICU patients, but only two are validated for the diagnosis of delirium in mechanically ventilated patients (i.e., the intensive care delirium screening checklist [ICDSC] [48] and the confusion assessment method for the ICU [CAM-ICU] [49]). A translated Korean version of CAM-ICU with proven high sensitivity and specificity is also available [50]. Use of the RASS for the assessment of sedation followed by the CAM-ICU or the ICDSC is one approach for the establishment of a delirium diagnosis in ICU patients. A diagnosis of delirium using the CAM-ICU requires (1) an acute change or fluctuation in mental status (feature 1); (2) inattention (feature 2); and (3) one of the following: (a) disorganized thinking (feature 3) or (b) an altered level of consciousness (feature 4). Importantly, though, only patients with a RASS score of three points or more are considered alert enough to respond to the CAM-ICU test and thus be assessed in this manner for delirium. Separately, when making a diagnosis using the ICDSC, patients who score at least four points are considered to have the condition.

Some studies have suggested that delirium evaluations should not be performed while the patient is sedated [51,52]. It is true that a small subset of patients (approximately 10\%) may have rapidly reversible sedation-related delirium that dissipates after sedation is discontinued. Unfortunately, a study evaluating rapidly reversible delirium found that most patients continued to have persistent delirium even after sedation was interrupted. If possible, the assessment of delirium should be performed following sedation interruption. The evaluation of delirium should not be discontinued, because a low percentage of patients experience sedative delirium. 
Laboratory evaluations of patients with delirium should include serum electrolyte, creatinine, glucose, and calcium concentrations as well as a complete blood count, urinalysis, and urine culture. Drug levels, toxicology screening, liver function testing, and arterial blood gas measurements should follow if the cause remains undetermined. Neuroimaging, lumbar puncture, and electroencephalography (EEG) are not required in most patients with delirium; however, they are recommended in specific clinical scenarios, including in efforts to elucidate delirium causes that remain obscure after routine testing. EEG is also useful in patients with altered consciousness to exclude seizures, especially nonconvulsive or subclinical seizures, and to confirm the diagnosis of specific metabolic encephalopathies or infectious encephalitides that have characteristic EEG patterns $[53,54]$.

\section{PREDICTION}

The early recognition of delirium is important for critically ill patients in the ICU. Predictive models that include delirium risk factors at the time of ICU admission and during the 24 hours after ICU admission have already been validated. The Prediction of Delirium in ICU Patients (PRE-DELIRIC) model uses 10 predictors-specifically, age, Acute Physiology and Chronic Health Evaluation II score, admission group, urgent admission, infection, coma, sedation, morphine use, urea level, and metabolic acidosis - and has an area under the receiver operating characteristic (AUROC) curve value of 0.77 (95\% confidence interval [CI], 0.74 to 0.79) [55]. In comparison, the early (E)-PRE-DELIRIC model uses nine predictors (age, history of cognitive impairment, history of alcohol abuse, blood urea nitrogen, admission category, urgent admission, mean arterial blood pressure, use of corticosteroids, and respiratory failure) and has an AUROC curve value of 0.76 (95\% CI, 0.73 to 0.77) [56]. Because the PREDELIRIC and E-PRE-DELIRIC models have similar predictive values, the decision of which model to choose can be based on the availability of information about predictors. Both models are based on screening using only the CAM-ICU.

Table 2. Recommendations and strength levels of evidence for delirium prevention and management [57]

\begin{tabular}{|c|c|}
\hline Question & Recommendation \\
\hline \multicolumn{2}{|l|}{ A. Nonpharmacologic prevention and treatment } \\
\hline \multicolumn{2}{|l|}{ Single component } \\
\hline $\begin{array}{l}\text { Should a single-component, nonpharmacologic strategy } \\
\text { not solely focused on sleep improvement or early mobili- } \\
\text { zation (vs. no such strategy) be used to reduce delirium in } \\
\text { critically ill adults? }\end{array}$ & $\begin{array}{l}\text { Committee suggests not using bright light therapy to reduce delirium in critically ill } \\
\text { adults (conditional recommendation, moderate quality of evidence). }\end{array}$ \\
\hline \multicolumn{2}{|l|}{ Multicomponent } \\
\hline $\begin{array}{l}\text { Should a multicomponent, nonpharmacologic strategy (vs. } \\
\text { no such strategy) be used to reduce delirium in critically ill } \\
\text { adults? }\end{array}$ & $\begin{array}{l}\text { Committee suggests using a multicomponent, nonpharmacologic intervention that } \\
\text { is focused on (but not limited to) reducing modifiable risk factors for delirium, im- } \\
\text { proving cognition, and optimizing sleep, mobility, hearing, and vision in critically ill } \\
\text { adults (conditional recommendation, low quality of evidence). }\end{array}$ \\
\hline \multicolumn{2}{|l|}{ B. Pharmacologic prevention and treatment } \\
\hline $\begin{array}{l}\text { Should a pharmacologic agent (vs. no use of this agent) be } \\
\text { used to "prevent" delirium in all critically ill adults? }\end{array}$ & $\begin{array}{l}\text { Committee suggests not using haloperidol, an atypical antipsychotic, dexmedetomi- } \\
\text { dine, a HMG-CoA reductase inhibitor (i.e., statin), or ketamine to prevent delirium } \\
\text { in all critically ill adults (conditional recommendation, very low to low quality of } \\
\text { evidence). }\end{array}$ \\
\hline $\begin{array}{l}\text { Should a pharmacologic agent (vs. no use of this agent) be } \\
\text { used to "treat subsyndromal delirium" in all critically ill } \\
\text { adults with subsyndromal delirium? }\end{array}$ & $\begin{array}{l}\text { Committee suggests not using haloperidol or an atypical antipsychotic to treat sub- } \\
\text { syndromal delirium in critically ill adults (conditional recommendation, very low to } \\
\text { low quality of evidence). }\end{array}$ \\
\hline $\begin{array}{l}\text { Should a pharmacologic agent (vs. no use of this agent) be } \\
\text { used to treat delirium in all critically ill adults with delirium? }\end{array}$ & - \\
\hline 1. Antipsychotic/statin & $\begin{array}{l}\text { Committee suggests not routinely using haloperidol, an atypical antipsychotic, or a } \\
\text { HMG-CoA reductase inhibitor (i.e., a statin) to treat delirium (conditional recom- } \\
\text { mendation, low quality of evidence). }\end{array}$ \\
\hline 2. Dexmedetomidine & $\begin{array}{l}\text { Committee suggests using dexmedetomidine for delirium in mechanically ventilated } \\
\text { adults where agitation precludes weaning/extubation (conditional recommenda- } \\
\text { tion, low quality of evidence). }\end{array}$ \\
\hline
\end{tabular}

HMG-CoA: $\beta$-hydroxy $\beta$-methylglutaryl-coenzyme A. 


\section{PREVENTION AND MANAGEMENT}

The Society of Critical Care Medicine recently issued the 2018 Clinical Practice Guidelines for the Prevention and Management of Pain, Agitation/Sedation, Delirium, Immobility, and Sleep Disruption in Adult Patients in the ICU (PADIS) [57]. Compared with the 2013 guidelines [9], these new 2018 guidelines include two inextricably-related clinical care topics (immobility and sleep), involved patients as collaborators and coauthors, and invited panelists from high-income countries to include insights from diverse practices and expertise from the global critical care community. It is believed that these factors will promote opinions from the guidelines to be more effectively applied in clinical practice.

Critically ill adults should be regularly assessed for delirium using a valid tool and predictive models $[55,56]$ that include delirium risk factors at the time of ICU admission and during the first 24 hours thereafter. These tools have been validated and can be used to predict delirium in critically ill adults. Table 2 presents a summary of the questions and recommendations (and the strength of evidence for each) for delirium prevention and management included in the 2018 PADIS guidelines [57].

\section{Nonpharmacologic Prevention and Treatment}

Most ICUs employ nonpharmacologic methods to reduce or prevent delirium. Regularly allaying anxiety and orienting patients, reducing environmental noise and the use of alarms, establishing light use consistent with day-night circadian cycles, and encouraging early mobility are some examples of strategies. A before-and-after study found that the use of a delirium monitoring/management and early exercise/mobility bundle (i.e., awakening and breathing coordination, delirium monitoring/management, and early exercise/mobility [ABCDE]) was significantly associated with reduced delirium in patients [58]. A revised and expanded ABCDEF bundle that included a different focus on " $\mathrm{A}$ " (assessment and treatment of pain) and the addition of " $\mathrm{F}$ " (family engagement) was evaluated using a large, multicenter, before-and-after cohort study. In this study, delirium was also assessed using the CAM-ICU. The adjusted analysis revealed that improvements in bundle compliance were significantly associated with reduced mortality rates and more ICU days without coma or delirium [59].

Disruption of the sleep-wake cycle in the ICU is another risk factor for delirium. When possible, maintaining an optimal sleep-wake cycle using either nonpharmacologic or pharmacologic means may help to prevent delirium [60].

\section{Pharmacologic Prevention and Treatment}

There is no evidence available to date that the routine use of antipsychotic therapy for the treatment of delirium is efficacious [61-64]. The Haloperidol Effectiveness in ICU Delirium trial found no benefit of treatment with haloperidol. However, such may be considered in the treatment of acute agitation (hyperactive delirium) [61]. Use of all antipsychotic agents should be discontinued immediately following the resolution of the patient's distress symptoms. The committee suggests not using haloperidol, an atypical antipsychotic; dexmedetomidine, a $\beta$-hydroxy $\beta$-methylglutaryl-coenzyme A reductase inhibitor (i.e., statin); or ketamine to prevent delirium in critically ill adults, although this is a conditional recommendation with a very low to low quality of evidence. The committee also recommends avoiding routinely employing the above pharmacologic agents (conditional recommendation, low quality of evidence) and using dexmedetomidine for the treatment of delirium in mechanically ventilated adults who have agitation that precludes weaning/extubation (conditional recommendation, low quality of evidence). Recommendations for delirium treatment strategies suggest that the application of dexmedetomidine may be a better treatment strategy than one that is based on benzodiazepine administration. A single-cohort randomized trial evaluated dexmedetomidine's role as a treatment for agitation precluding ventilator liberation [65].

Dexmedetomidine is a highly selective, centrally acting alpha-2-agonist with anxiolytic, sedative, and some analgesic effects. It has no deleterious effects on respiratory drive. An initial loading dose is typically not performed, but can be administered if necessary [66]. The initial loading dose may cause transient hypotension or hypertension, depending upon whether vasodilation from the activation of central alpha 2a receptors or vasoconstriction from the activation of peripheral alpha $2 \mathrm{~b}$ receptors predominates. The usual dexmedetomidine maintenance dose is 0.2 to $0.7 \mu \mathrm{g} / \mathrm{kg} / \mathrm{hr}$, with dosage increases suggested to happen as needed not more frequently than every 30 minutes. There are no specific guidelines for modifying the dose for elderly patients or patients who have renal or hepatic impairment. It is prudent to start at the low end of the dosage range and titrate slowly in accordance with the patient's response. The variability in patient response to dexmedetomidine may be due to as-yet-unidentified patient characteristics, pharmacokinetics, and genetic polymorphisms [67].

The results of another study indicated that prophylactic nighttime administration of dexmedetomidine results in a rate of ICU delirium prevention of $80 \%$ (compared with $20 \%$ using a placebo) during ICU admittance [68]. This random- 
ized trial found that fewer of the patients who receive dexmedetomidine require a fentanyl infusion during their ICU stay (76\% vs. 94\%, respectively; $\mathrm{P}=0.02$ ). Results obtained using the Leeds Sleep Evaluation Questionnaire indicated that sleep quality was no different between the dexmedetomidine and placebo groups. The lower proportion of patients requiring a fentanyl infusion during the ICU stay in the intervention group may be related to a dexmedetomidine-associated analgesic effect; the rates of fentanyl infusion at the time of randomization were frequent and similar between the two groups. These potential coanalgesic and opioid-sparing effects merit further study given the increasing concerns about opioid consumption during hospitalization.

\section{CONCLUSIONS}

Delirium is a disturbance of consciousness and cognition that occurs during a short period of time. It is associated with significantly increased morbidity and mortality rates in critically ill patients. Subtypes of delirium include hyperactive, hypoactive, and mixed. Many risk factors are associated with delirium; some are modifiable or preventable by the clinician. There are multiple validated assessment tools available to evaluate delirium. Patients in the ICU must first be assessed for sedation levels and then for the presence of delirium, using scales such as the CAM-ICU or the ICDSC.

Minimizing sedation using tactics such as daily interruptions of sedation can help to reduce exposure to delirogenic psychoactive medications. The application of benzodiazepines should be avoided in the ICU, except for the treatment of specific conditions. Alternatives available for sedation include haloperidol, atypical antipsychotics, dexmedetomidine, and remifentanil. However, additional pharmacologic intervention studies should be performed to determine the roles of these medications in the prevention and treatment of delirium.

\section{CONFLICT OF INTEREST}

No potential conflict of interest relevant to this article was reported.

\section{ORCID}

Seung Yong Park https://orcid.org/0000-0002-3774-4375

Heung Bum Lee https://orcid.org/0000-0002-8267-8434

\section{AUTHOR CONTRIBUTIONS}

Conceptualization: HBL. Data curation: SYP. Formal analysis: SYP. Methodology: SYP, HBL. Project administration: HBL. Visualization: SYP. Writing - original draft: SYP, HBL. Writing review \& editing: HBL.

\section{REFERENCES}

1. Inouye SK, Rushing JT, Foreman MD, Palmer RM, Pompei P. Does delirium contribute to poor hospital outcomes? A threesite epidemiologic study. J Gen Intern Med 1998;13:234-42.

2. Pandharipande P, Cotton BA, Shintani A, Thompson J, Costabile S, Truman Pun B, et al. Motoric subtypes of delirium in mechanically ventilated surgical and trauma intensive care unit patients. Intensive Care Med 2007;33:1726-31.

3. Dubois MJ, Bergeron N, Dumont M, Dial S, Skrobik Y. Delirium in an intensive care unit: a study of risk factors. Intensive Care Med 2001;27:1297-304.

4. Ely EW, Gautam S, Margolin R, Francis J, May L, Speroff T, et al. The impact of delirium in the intensive care unit on hospital length of stay. Intensive Care Med 2001;27:1892-900.

5. Kiely DK, Jones RN, Bergmann MA, Marcantonio ER. Association between psychomotor activity delirium subtypes and mortality among newly admitted post-acute facility patients. J Gerontol A Biol Sci Med Sci 2007;62:174-9.

6. Marcantonio E, Ta T, Duthie E, Resnick NM. Delirium severity and psychomotor types: their relationship with outcomes af ter hip fracture repair. J Am Geriatr Soc 2002;50:850-7.

7. Camus V, Gonthier R, Dubos G, Schwed P, Simeone I. Etiologic and outcome profiles in hypoactive and hyperactive subtypes of delirium. J Geriatr Psychiatry Neurol 2001;13:38-42.

8. Ely EW, Shintani A, Truman B, Speroff T, Gordon SM, Harrell FE Jr, et al. Delirium as a predictor of mortality in mechanically ventilated patients in the intensive care unit. JAMA 2004; 291:1753-62.

9. Barr J, Fraser GL, Puntillo K, Ely EW, Gélinas C, Dasta JF, et al. Clinical practice guidelines for the management of pain, agitation, and delirium in adult patients in the intensive care unit. Crit Care Med 2013;41:263-306.

10. Vincent JL, Shehabi Y, Walsh TS, Pandharipande PP, Ball JA, Spronk P, et al. Comfort and patient-centred care without excessive sedation: the eCASH concept. Intensive Care Med 2016;42:962-71.

11. Marra A, Ely EW, Pandharipande PP, Patel MB. The ABCDEF bundle in critical care. Crit Care Clin 2017;33:225-43.

12. Pandharipande PP, Girard TD, Jackson JC, Morandi A, Thomp- 
son JL, Pun BT, et al. Long-term cognitive impairment after critical illness. N Engl J Med 2013;369:1306-16.

13. Jackson JC, Gordon SM, Hart RP, Hopkins RO, Ely EW. The association between delirium and cognitive decline: a review of the empirical literature. Neuropsychol Rev 2004;14:87-98.

14. Jackson JC, Mitchell N, Hopkins RO. Cognitive functioning, mental health, and quality of life in ICU survivors: an overview. Psychiatr Clin North Am 2015;38:91-104.

15. Deutschman CS, Neligan PJ. Evidence-based practice of critical care. 2nd ed. Philadelphia: Elsevier; 2016.

16. Ouimet S, Kavanagh BP, Gottfried SB, Skrobik Y. Incidence, risk factors and consequences of ICU delirium. Intensive Care Med 2007;33:66-73.

17. Pandharipande P, Shintani A, Peterson J, Pun BT, Wilkinson GR, Dittus RS, et al. Lorazepam is an independent risk factor for transitioning to delirium in intensive care unit patients. Anesthesiology 2006;104:21-6.

18. Inouye SK, Charpentier PA. Precipitating factors for delirium in hospitalized elderly persons: predictive model and interrelationship with baseline vulnerability. JAMA 1996;275:852-7.

19. McNicoll L, Pisani MA, Zhang Y, Ely EW, Siegel MD, Inouye SK. Delirium in the intensive care unit: occurrence and clinical course in older patients. J Am Geriatr Soc 2003;51:591-8.

20. Lin SM, Huang CD, Liu CY, Lin HC, Wang CH, Huang PY, et al. Risk factors for the development of early-onset delirium and the subsequent clinical outcome in mechanically ventilated patients. J Crit Care 2008;23:372-9.

21. McKinley S, Fien M, Elliott R, Elliott D. Sleep and psychological health during early recovery from critical illness: an observational study. J Psychosom Res 2013;75:539-45.

22. Kamdar BB, Needham DM, Collop NA. Sleep deprivation in critical illness: its role in physical and psychological recovery. J Intensive Care Med 2012;27:97-111.

23. Van Rompaey B, Elseviers MM, Schuurmans MJ, ShortridgeBaggett LM, Truijen S, Bossaert L. Risk factors for delirium in intensive care patients: a prospective cohort study. Crit Care 2009;13:R77.

24. Micek ST, Anand NJ, Laible BR, Shannon WD, Kollef MH. Delirium as detected by the CAM-ICU predicts restraint use among mechanically ventilated medical patients. Crit Care Med 2005; 33:1260-5.

25. Pandharipande P, Cotton BA, Shintani A, Thompson J, Pun BT, Morris JA Jr, et al. Prevalence and risk factors for development of delirium in surgical and trauma intensive care unit patients. J Trauma 2008;65:34-41.

26. Litaker D, Locala J, Franco K, Bronson DL, Tannous Z. Preoperative risk factors for postoperative delirium. Gen Hosp Psy- chiatry 2001;23:84-9.

27. Olin K, Eriksdotter-Jönhagen M, Jansson A, Herrington MK, Kristiansson M, Permert J. Postoperative delirium in elderly patients after major abdominal surgery. Br J Surg 2005;92:155964.

28. Vaurio LE, Sands LP, Wang Y, Mullen EA, Leung JM. Postoperative delirium: the importance of pain and pain management. Anesth Analg 2006;102:1267-73.

29. Morrison RS, Magaziner J, Gilbert M, Koval KJ, McLaughlin MA, Orosz G, et al. Relationship between pain and opioid analgesics on the development of delirium following hip fracture. J Gerontol A Biol Sci Med Sci 2003;58:76-81.

30. Choi JG. Delirium in the intensive care unit. Korean J Anesthesiol 2013;65:195-202.

31. Schreiber MP, Colantuoni E, Bienvenu OJ, Neufeld KJ, Chen KF, Shanholtz C, et al. Corticosteroids and transition to delirium in patients with acute lung injury. Crit Care Med 2014;42: 1480-6.

32. Kazmierski J, Banys A, Latek J, Bourke J, Jaszewski R. Cortisol levels and neuropsychiatric diagnosis as markers of postoperative delirium: a prospective cohort study. Crit Care 2013; 17:R38.

33. Trzepacz PT. The neuropathogenesis of delirium: a need to focus our research. Psychosomatics 1994;35:374-91.

34. Mach JR Jr, Dysken MW, Kuskowski M, Richelson E, Holden L, Jilk KM. Serum anticholinergic activity in hospitalized older persons with delirium: a preliminary study. J Am Geriatr Soc 1995;43:491-5.

35. Hshieh TT, Fong TG, Marcantonio ER, Inouye SK. Cholinergic deficiency hypothesis in delirium: a synthesis of current evidence. J Gerontol A Biol Sci Med Sci 2008;63:764-72.

36. Plaschke K, Hill H, Engelhardt R, Thomas C, von Haken R, Scholz M, et al. EEG changes and serum anticholinergic activity measured in patients with delirium in the intensive care unit. Anaesthesia 2007;62:1217-23.

37. Campbell N, Boustani M, Limbil T, Ott C, Fox C, Maidment I, et al. The cognitive impact of anticholinergics: a clinical review. Clin Interv Aging 2009;4:225-33.

38. Seamans JK, Floresco SB, Phillips AG. D1 receptor modulation of hippocampal-prefrontal cortical circuits integrating spatial memory with executive functions in the rat. J Neurosci 1998;18:1613-21.

39. Hirano H, Day J, Fibiger HC. Serotonergic regulation of acetylcholine release in rat frontal cortex. J Neurochem 1995;65: 1139-45.

40. van Munster BC, Bisschop PH, Zwinderman AH, Korevaar JC, Endert E, Wiersinga WJ, et al. Cortisol, interleukins and S100B 
in delirium in the elderly. Brain Cogn 2010;74:18-23.

41. Pfister D, Siegemund M, Dell-Kuster S, Smielewski P, Rüegg S, Strebel SP, et al. Cerebral perfusion in sepsis-associated delirium. Crit Care 2008;12:R63.

42. McGrane S, Girard TD, Thompson JL, Shintani AK, Woodworth A, Ely EW, et al. Procalcitonin and C-reactive protein levels at admission as predictors of duration of acute brain dysfunction in critically ill patients. Crit Care 2011;15:R78.

43. Devlin JW, Fong JJ, Howard EP, Skrobik Y, McCoy N, Yasuda C, et al. Assessment of delirium in the intensive care unit: nursing practices and perceptions. Am J Crit Care 2008;17:555-65.

44. Ramsay MA. Measuring level of sedation in the intensive care unit. JAMA 2000;284:441-2.

45. Riker RR, Picard JT, Fraser GL. Prospective evaluation of the Sedation-Agitation Scale for adult critically ill patients. Crit Care Med 1999;27:1325-9.

46. Sessler CN, Gosnell MS, Grap MJ, Brophy GM, O’Neal PV, Keane KA, et al. The Richmond Agitation-Sedation Scale: validity and reliability in adult intensive care unit patients. Am J Respir Crit Care Med 2002;166:1338-44.

47. Ely EW, Truman B, Shintani A, Thomason JW, Wheeler AP, Gordon S, et al. Monitoring sedation status over time in ICU patients: reliability and validity of the Richmond AgitationSedation Scale (RASS). JAMA 2003;289:2983-91.

48. Bergeron N, Dubois MJ, Dumont M, Dial S, Skrobik Y. Intensive Care Delirium Screening Checklist: evaluation of a new screening tool. Intensive Care Med 2001;27:859-64.

49. Ely EW, Margolin R, Francis J, May L, Truman B, Dittus R, et al. Evaluation of delirium in critically ill patients: validation of the Confusion Assessment Method for the Intensive Care Unit (CAM-ICU). Crit Care Med 2001;29:1370-9.

50. Heo EY, Lee BJ, Hahm BJ, Song EH, Lee HA, Yoo CG, et al. Translation and validation of the Korean confusion assessment method for the intensive care unit. BMC Psychiatry 2011; 11:94.

51. Patel SB, Poston JT, Pohlman A, Hall JB, Kress JP. Rapidly reversible, sedation-related delirium versus persistent delirium in the intensive care unit. Am J Respir Crit Care Med 2014;189: 658-65.

52. Haenggi M, Blum S, Brechbuehl R, Brunello A, Jakob SM, Takala J. Effect of sedation level on the prevalence of delirium when assessed with CAM-ICU and ICDSC. Intensive Care Med 2013;39:2171-9.

53. Jacobson SA, Leuchter AF, Walter DO, Weiner H. Serial quantitative EEG among elderly subjects with delirium. Biol Psychiatry 1993;34:135-40.

54. Hemphill JC. Disorders of consciousness in systemic diseas- es. In: Aminoff MJ, editor. Aminoff's neurology and general medicine. 3rd ed. New York: Churchill Livingstone: 2001. p. 1053.

55. van den Boogaard M, Schoonhoven L, Maseda E, Plowright C, Jones C, Luetz A, et al. Recalibration of the delirium prediction model for ICU patients (PRE-DELIRIC): a multinational observational study. Intensive Care Med 2014;40:361-9.

56. Wassenaar A, van den Boogaard M, van Achterberg T, Slooter AJ, Kuiper MA, Hoogendoorn ME, et al. Multinational development and validation of an early prediction model for delirium in ICU patients. Intensive Care Med 2015;41:1048-56.

57. Devlin JW, Skrobik Y, Gélinas C, Needham DM, Slooter AJ, Pandharipande PP, et al. Clinical practice guidelines for the prevention and management of pain, agitation/sedation, delirium, immobility, and sleep disruption in adult patients in the ICU. Crit Care Med 2018;46:e825-73.

58. Balas MC, Burke WJ, Gannon D, Cohen MZ, Colburn L, Bevil $\mathrm{C}$, et al. Implementing the awakening and breathing coordination, delirium monitoring/management, and early exercise/mobility bundle into everyday care: opportunities, challenges, and lessons learned for implementing the ICU Pain, Agitation, and Delirium Guidelines. Crit Care Med 2013;41(9 Suppl 1):S116-27.

59. Barnes-Daly MA, Phillips G, Ely EW. Improving hospital survival and reducing brain dysfunction at seven California community hospitals: implementing $\mathrm{PAD}$ guidelines via the $\mathrm{ABCDEF}$ bundle in 6,064 patients. Crit Care Med 2017;45:171-8.

60. Kamdar BB, King LM, Collop NA, Sakamuri S, Colantuoni E, Neufeld KJ, et al. The effect of a quality improvement intervention on perceived sleep quality and cognition in a medical ICU. Crit Care Med 2013;41:800-9.

61. Page VJ, Ely EW, Gates S, Zhao XB, Alce T, Shintani A, et al. Effect of intravenous haloperidol on the duration of delirium and coma in critically ill patients (Hope-ICU): a randomised, double-blind, placebo-controlled trial. Lancet Respir Med 2013;1:515-23.

62. Girard TD, Pandharipande PP, Carson SS, Schmidt GA, Wright $\mathrm{PE}$, Canonico AE, et al. Feasibility, efficacy, and safety of antipsychotics for intensive care unit delirium: the MIND randomized, placebo-controlled trial. Crit Care Med 2010;38:428-37.

63. Needham DM, Colantuoni E, Dinglas VD, Hough CL, Wozniak AW, Jackson JC, et al. Rosuvastatin versus placebo for delirium in intensive care and subsequent cognitive impairment in patients with sepsis-associated acute respiratory distress syndrome: an ancillary study to a randomised controlled trial. Lancet Respir Med 2016;4:203-12.

64. Devlin JW, Smithburger P, Kane JM, Fraser GL, Skrobik Y. In- 
tended and unintended consequences of constraining clinician prescribing: the case of antipsychotics. Crit Care Med 2016;44:1805-7.

65. Reade MC, Eastwood GM, Bellomo R, Bailey M, Bersten A, Cheung B, et al. Effect of dexmedetomidine added to standard care on ventilator-free time in patients with agitated delirium: a randomized clinical trial. JAMA 2016;315:1460-8.

66. Dasta JF, Kane-Gill SL, Durtschi AJ. Comparing dexmedetomidine prescribing patterns and safety in the naturalistic set- ting versus published data. Ann Pharmacother 2004;38:1130-5.

67. Holliday SF, Kane-Gill SL, Empey PE, Buckley MS, Smithburger PL. Interpatient variability in dexmedetomidine response: a survey of the literature. ScientificWorldJournal 2014;2014: 805013.

68. Skrobik Y, Duprey MS, Hill NS, Devlin JW. Low-dose nocturnal dexmedetomidine prevents ICU delirium: a randomized, placebo-controlled trial. Am J Respir Crit Care Med 2018;197: 1147-56. 